OPEN ACCESS

Edited by:

James K. Liu,

Rutgers University, USA

Reviewed by:

Paul Klimo,

Semmes-Murphey Clinic, USA

Ira M. Goldstein,

Rutgers University, USA

*Correspondence:

Meic H. Schmidt,

Department of Neurosurgery,

University of Utah,

175 North Medical Drive East,

Salt Lake City,

UT 84132, USA

neuropub@hsc.utah.edu

Specialty section: This article was submitted to Neurosurgery, a section of the

journal Frontiers in Surgery

Received: 26 January 2015

Paper pending published:

06 March 2015

Accepted: 10 May 2015

Published: 28 May 2015

Citation:

Bisson EF, Bowers CA, Hohmann SF and Schmidt MH (2015) Smoking is associated with poorer quality-based outcomes in patients hospitalized with spinal disease.

Front. Surg. 2:20.

doi: 10.3389/fsurg.2015.00020

\section{Smoking is associated with poorer quality-based outcomes in patients hospitalized with spinal disease}

\author{
Erica F. Bisson ${ }^{1}$, Christian A. Bowers ${ }^{1}$, Samuel F. Hohmann ${ }^{2}$ and Meic H. Schmidt ${ }^{1 *}$ \\ ${ }^{1}$ Department of Neurosurgery, Clinical Neurosciences Center, University of Utah, Salt Lake City, UT, USA, ${ }^{2}$ Comparative Data \\ and Informatics Research, University HealthSystem Consortium, Chicago, IL, USA
}

Study design: Retrospective cross-sectional database analysis.

Objective: The cost of spine surgery is growing exponentially, and cost-effectiveness is a critical consideration. Smoking has been shown to increase hospital costs in general surgery, but this impact has not been reported in patients with spinal disease. The objective of this work was to evaluate the effect of smoking on cost and complications in a large sample of patients admitted for treatment of spinal disease.

Methods: In 2012, the authors identified all inpatient admissions to all University HealthSystem Consortium (UHC) hospitals from 2005 to 2011 for spinal disease based on the principal diagnosis ICD-9-CM codes from the prospectively collected UHC database. Patient outcomes - including length of stay; complication, readmission, intensive care unit admission rates; and total cost - were compared for non-obese smokers and non-smokers using a two-sample $t$-test.

Results: There were 137,537 patients, including 136,511 (122,608 non-smokers and 13,903 smokers) in the 4 largest diagnostic groups. Smoking was associated with increased complications and worse outcomes in three of these four groups. All outcomes in the two largest groups - fracture and dorsopathy - were worse in the smoking patients.

Conclusion: Smoking patients admitted for spinal disease in the sample had worse outcomes, increased complications, and higher costs than their non-smoking counterparts. In the current health-care climate focused on cost-effectiveness, smoking represents a potentially modifiable area for cost reduction.

Keywords: smoking, spine, surgery, healthcare costs, value, modifiable risk factors, patient outcomes, quality improvement

\section{Introduction}

Approximately 1.2 million spinal surgeries are performed annually in the United States for traumatic, oncologic, degenerative, and other conditions $(1,2)$. Fusion surgeries alone cost more than $\$ 10$ billion, and the overall cost of spine care approaches $\$ 100$ billion, accounting for nearly $10 \%$ of the nation's total healthcare expenditures $(1,2)$. While the annual increase in the cost of healthcare in

Abbreviations: ICU, intensive care unit; LOS, length of stay; UHC, University HealthSystem Consortium. 
general has been at its lowest recorded rates of the last 50 years, at 3.8 and $3.9 \%$, respectively, for 2009 and 2010, spine care expenditures as recently as 2005 were estimated to have increased $65 \%$ from their 1997 levels (3). The reason for this exponential increase remains unclear.

The shift over the last few decades to the use of more instrumentation in spinal surgery is well-documented, with increasing numbers of both instrumented levels per spinal procedure and spinal fusions altogether (4). Some have argued that the cost of instrumentation has played a large role in the cost increase seen for spinal surgery in the last decade, but there are likely to be other potentially modifiable variables that affect the overall cost of hospitalization for a patient with spinal disease. Recently, there has been a call by the Institutes of Medicine (5) for research on cost-effectiveness in many fields of medicine, including spine surgery, to help define and improve value in medical care. To address this call, the medical community will need not only to identify the optimal treatment strategies based on cost-effective studies but also to understand patient and hospital variables that may impact the overall cost, both monetary and non-monetary, of these procedures.

A recent review summarized the results from multiple studies documenting the negative impact of smoking on the overall hospital care of surgical patients, including increased risk of perioperative complications, morbidity, mortality, and admission to the intensive care unit (ICU) in patients undergoing orthopedic, general surgery, plastic surgery, and cardiac procedures (6-10). The complications associated with smoking include wound infections, delayed wound healing, pneumonia, and myocardial infarction (9). Even pediatric surgery is affected, as pediatric patients with more secondhand smoking exposure have been shown to have higher rates of anesthesia-associated respiratory complications (9). In addition to its impact on the medical care of patients, smoking negatively affects costs associated with surgery. In 2012, Kamath et al. (10) reported that among veterans undergoing general surgical procedures, those who used tobacco had significantly higher hospital-associated costs. With approximately 10 million surgical procedures currently done on smokers in the United States annually, including spinal procedures, it is imperative that the contribution of this potentially modifiable risk to the overall hospital cost of these procedures is defined (10).

As payment for the delivery of healthcare is changing, quality improvement and cost reduction in medical care are increasing on the agenda for all healthcare institutions. The goal of this study was to evaluate the association of smoking with cost and complications in a large sample of patients admitted for spinal disease at both academic and non-academic institutions using the prospectively collected data in the University HealthSystem Consortium (UHC) database. Although the use of an administrative database limits the ability to evaluate individual patient-level data, it nevertheless provides the opportunity for a preliminary analysis that may be the basis for future in-depth investigation.

\section{Materials and Methods}

\section{UHC Database}

The UHC is a network of 116 academic medical centers and 276 of their affiliated hospitals, comprising $>90 \%$ of non-profit academic medical centers in the country. The UHC database contains demographic, financial, administrative, diagnostic, and procedural information in addition to specific hospital stay information such as medication use, ICU admission rates/length of stay (LOS), total hospital LOS, morbidity rates, mortality rates, complications, and readmission rates $(11,12)$. The UHC database provides the ICD-9-CM code for almost every hospital discharge, and although it was originally used for improving cost-effectiveness, quality healthcare, safety, and overall outcomes through comparing the various member institutions, multiple groups in other specialties, especially general surgery, have used this database to identify specific variables that impact outcomes (11-15). The patient data set was de-identified before data gathering and therefore is exempt from institutional review board approval.

\section{Patient Population}

In 2012, the authors queried the UHC database in a retrospective cross-sectional analysis of all UHC hospitals from 2005 to 2011 to identify all inpatient admissions for treatment of spinal disease based on the principal diagnosis ICD-9-CM codes, including cord injury, congenital, curvature, dislocation, dorsopathy, which is defined as "a condition in which there is a deviation from or interruption of the normal structure or function of the spine," fracture, and sprains/strains. Obese patients (defined either by a primary ICD-9-CM code of "obesity" or "morbid obesity" or by a body mass index $>25$ ) were excluded because obesity is a known independent risk factor for adverse outcomes and is associated with increased cost, more complications, and higher infection rates in spine surgery patients (16-19). The remaining non-obese patients with each UHC database diagnosis code were then further categorized as smokers or non-smokers. The primary aim of this study was to evaluate whether smoking has an association with either cost or quality-based outcomes in specific cohorts of patients admitted with spinal disease as their principal diagnosis.

\section{Outcomes}

Primary outcomes were hospital LOS, ICU admission, 7-, 14-, and 30-day readmission rates, complication rates, and total direct cost associated with the hospital admission. Complications were defined by ICD-9-CM code and included a list of 39 potential surgical complications, such as wound infection, myocardial infarction, and urinary tract infection (see Appendix).

\section{Statistical Analysis}

The authors compared the outcomes for all non-obese spine patients that were non-smokers with outcomes for smokers using a two-sample $t$-test with a $95 \%$ confidence interval. Pooled variance was appropriate for almost all of the comparisons. Statistical analysis was performed using SAS, Enterprise Guide Version 4.3.

\section{Results}

There were a total of 137,537 non-obese patients admitted with spinal disease during the study period among all pathology groups, including 136,511 total patients among the dorsopathy, fracture, curvature, and congenital groups, the four largest cohorts. Approximately $10 \%$ of these were smokers 
TABLE 1 | Outcomes of patients admitted for spinal treatment for dorsopathy.

\begin{tabular}{lccc}
\hline & Smoker & Non-smoker & $\boldsymbol{p}$-Value \\
\hline Mean LOS (days) & 4.87 & 3.77 & 0.00 \\
Mean ICU admission rate (\%) & 18 & 12 & 0.00 \\
Mean complication rate (\%) & 6.97 & 5.24 & 0.00 \\
Mean 7-day readmission rate (\%) & 2.80 & 2.04 & 0.00 \\
Mean 14-day readmission rate (\%) & 4.84 & 3.28 & 0.00 \\
Mean 30-day readmission rate (\%) & 6.89 & 4.81 & 0.00 \\
Mean total cost $(\$)$ & 23,185 & 18,889 & 0.00 \\
\hline
\end{tabular}

LOS, length of stay; ICU, intensive care unit.

TABLE 2 | Outcomes of patients admitted for spinal treatment for fracture.

\begin{tabular}{lccc}
\hline & Smoker & Non-smoker & $\boldsymbol{p}$-Value \\
\hline Mean LOS (days) & 19.13 & 14.37 & 0.00 \\
Mean ICU admission rate (\%) & 71 & 58 & 0.00 \\
Mean complication rate (\%) & 26.90 & 19.78 & 0.00 \\
Mean 7-day readmission rate (\%) & 3.98 & 2.60 & 0.00 \\
Mean 14-day readmission rate (\%) & 7.03 & 4.83 & 0.00 \\
Mean 30-day readmission rate (\%) & 11.22 & 7.47 & 0.00 \\
Mean total cost (\$) & 62,039 & 45,699 & 0.00 \\
\hline
\end{tabular}

LOS, length of stay; ICU, intensive care unit.

$(13,903)$ and almost $90 \%$ were non-smokers $(122,608)$. The nonsmoking patients included 92,553 dorsopathy patients, 16,584 fracture patients, 1,962 congenital patients, and 11,509 curvature patients, whereas the smoking patients included 11,384 dorsopathy patients, 1,052 fracture patients, 228 congenital patients, and 1,239 curvature patients.

Statistical analysis demonstrated that smoking was associated with increased complications and worse outcomes in three of the four largest diagnosis groups. Smokers in the dorsopathy group had worse outcomes across all measured variables when compared with non-smokers (Table 1), with a mean LOS that was 1.01 days longer $(p<0.001)$, a $6 \%$ higher ICU admission rate $(p<0.001)$, a complication rate that was $1.73 \%$ higher $(p<0.001)$, and a $0.76 \%$ higher 7 -day readmission rate $(p=0.00)$, a $1.56 \%$ higher 14 -day readmission rate $(p<0.001)$, and a $2.08 \%$ higher 30 -day readmission rate $(p<0.001)$. Smoking patients in the fracture group also had significantly worse outcomes across all measured outcomes (Table 2), with a 4.76-day longer mean LOS $(p<0.001)$, a $13 \%$ higher ICU admission rate $(p<0.001)$, a $7.12 \%$ higher complication rate $(p<0.001)$, and a $1.38 \%$ higher 7 -day readmission rate $(p<0.01)$, a $2.25 \%$ higher 14 -day readmission rate $(p<0.01)$, and a $3.75 \%$ higher 30 -day readmission rate $(p<0.001)$. The smokers in the congenital group had worse LOS ( 0.57 days longer, $p=0.04$ ) and higher 30 -day readmission rates $(3.54 \%$ higher, $p=0.02)$, but there was not a significant difference in the other measured outcomes of ICU admission, complication rate, and 7- and 14-day readmission rates (Table 3). Finally, the smokers in the curvature group had worse 14 -day $(1.88 \%$ higher, $p<0.01)$ and 30 -day (3.04\% higher, $p<0.001$ ) readmission rates (Table 4 ), but there was not a significant difference in the other measured outcomes.

Total hospital costs were significantly higher in smokers with dorsopathy, congenital, and fracture as primary diagnosis codes (Tables 1-3). The total hospital cost for patients with dorsopathy
TABLE 3 | Outcomes of patients admitted for spinal treatment for congenital disease.

\begin{tabular}{lccc}
\hline & Smoker & Non-smoker & $\boldsymbol{p}$-Value \\
\hline Mean LOS (days) & 4.91 & 4.34 & 0.04 \\
Mean ICU admission rate (\%) & 14 & 10 & 0.09 \\
Mean complication rate (\%) & 5.26 & 6.47 & 0.43 \\
Mean 7-day readmission rate (\%) & 3.51 & 2.09 & 0.17 \\
Mean 14-day readmission rate (\%) & 4.82 & 3.47 & 0.29 \\
Mean 30-day readmission rate (\%) & 8.33 & 4.79 & 0.02 \\
Mean total cost (\$) & 28,889 & 24,642 & 0.01 \\
\hline
\end{tabular}

LOS, length of stay; ICU, intensive care unit.

TABLE 4 | Outcomes of patients admitted for spinal treatment for curvature.

\begin{tabular}{lccc}
\hline & Smoker & Non-smoker & $\boldsymbol{p}$-Value \\
\hline Mean LOS (days) & 6.89 & 6.78 & 0.63 \\
Mean ICU admission rate (\%) & 35 & 33 & 0.47 \\
Mean complication rate (\%) & 12.35 & 11.94 & 0.68 \\
Mean 7-day readmission rate (\%) & 3.13 & 2.46 & 0.15 \\
Mean 14-day readmission rate (\%) & 6.46 & 4.58 & 0.00 \\
Mean 30-day readmission rate (\%) & 10.17 & 7.13 & 0.00 \\
Mean total cost (\$) & 40,674 & 39,850 & 0.51 \\
\hline
\end{tabular}

LOS, length of stay; ICU, intensive care unit.

was $\$ 23,185$ for smokers vs. $\$ 18,889$ for non-smokers $(p<0.001)$. Costs for smokers with fractures were $\$ 62,039$ while those for nonsmokers with fractures were $\$ 45,699(p<0.001)$, and the total direct cost for smokers treated for congenital causes was $\$ 28,889$ compared with $\$ 24,642$ for non-smokers $(p=0.01)$.

\section{Discussion}

Despite abundant evidence documenting the negative impact of smoking on surgical outcomes and cost, the literature documenting the negative association in patients with spinal disease is scant. The authors present evidence of increased costs associated with smoking in patients admitted for treatment of spinal disease. Smoking in the dorsopathy and fracture groups was associated with worse outcomes across all the study variables of LOS, ICU admission, 7-, 14-, and 30-day readmission rates, complication rates, and, ultimately, total direct cost. Patients in the congenital group who smoked had also significantly longer LOS, increased total direct cost, and higher 30-day readmission rates. Smokers in the curvature group had higher 14- and 30-day readmission rates when compared with non-smokers. The total direct cost of care was also much higher in smoking patients, and the difference was statistically significant for patients with dorsopathy, fracture, and congenital disease with a difference of $\$ 4,296, \$ 16,370$, and $\$ 4,247$, respectively. In fracture patients, this increase in total cost was more than $25 \%$ of the overall direct cost of the hospitalization.

Although an avalanche of research has documented the harmful health effects of cigarette smoking, it remains the leading preventable cause of morbidity and mortality in the U.S. and accounts for $6-8 \%$ of national health-care costs $(10,20,21)$. With an estimated $30 \%$ smoking incidence among patients undergoing elective general surgery, over 10 million surgical procedures are performed on smokers annually in the U.S. (10). Smoking in surgical patients has been shown to be associated with increased 
complication rates including increased mortality, wound infection, reoperation rates, ICU stay, overall LOS, 30-day mortality, 1 -year mortality, and numerous other negative pulmonary, cardiovascular, and wound healing effects $(6,8-10,18,20,22-25)$, all of which are associated with increased healthcare costs (10, 26-28).

The socioeconomic burden of spinal care, both operative and non-operative, on healthcare costs is substantial (1). Smoking has been shown repeatedly to lead to worse fusion rates and increased surgical site infections (18, 29-31); however, some large studies of hundreds of patients describing the effects of cigarette smoking in spinal surgery have not found smoking to be associated with negative outcomes or complications in the surgical treatment of cervical spondylotic myelopathy, adult deformity surgery, decompression/fusion in degenerative lumbar spinal stenosis, multi-level cervical spine decompression, and anterior cervical spine surgery (32-36). Nevertheless, a recent subset analysis of the SPORT spinal stenosis cohort showed that all patient subgroups with more than 50 patients improved with surgical treatment except for smokers, as smoking was an independent risk factor for not improving with surgical treatment (37). A separate large study with 2-year follow-up of 4,555 patients who underwent surgery for lumbar spinal stenosis, with or without fusion, recently showed that smokers were more likely to be dissatisfied with surgery, used analgesics more regularly, and were less likely to have significant improvement in ambulation (38). An additional study of 203 patients who had lumbar decompression and posterolateral fusion found that smokers had less leg pain relief when compared with their non-smoking counterparts (39). Lastly, a study of 23 patients also showed that, compared with smokers, non-smokers had more postoperative relief of arm pain after anterior cervical decompression and fusion with a specific fusion cage (40).

Given the deleterious effects of smoking on surgical patients, it is not surprising that the benefits of perioperative smoking cessation, including improved surgical outcomes and fewer wound and other postoperative complications, are well-documented in multiple studies and systematic reviews (9, 10, 41-45). Furthermore, one orthopedic study evaluating total knee and hip arthroplasty demonstrated perioperative smoking cessation led to an overall reduction in the cost of care (22). Perioperative smoking cessation is a unique opportunity to reduce complications and the overall cost of healthcare, because surgery is one of the rare occasions where continued smoking may cause immediate negative consequences for the patient, in contrast to the typically delayed consequences of smoking $(9,20)$. Spinal surgery provides a critical opportunity since studies have shown that patients undergoing major surgery, as opposed to an outpatient procedure, have rates of smoking cessation as high as $35-50 \%$, with some patients continuing smoking cessation even after their recovery (20).

\section{References}

1. Teichner M. A New Hope for Back Pain Sufferers? CBS News (2012). Available from: http://www.cbsnews.com/8301-3445_162-57428677/a-new-hope-forback-pain-sufferers/

2. Eisner W. Spine Surgeons Respond to Martin-Deyo Study in JAMA. (2012). Available from: http://www.spine-health.com/physicians/spine-surgeons-respondmartin-deyo-study-jama
The most significant limitation of this study is the nature of the data collection. The number of patients $(>100,000)$ precludes the data acquisition and subsequent analysis of specific individual spinal pathology characteristics (e.g., radiographic extent of spinal stenosis, symptom type/duration) other than the basic information provided by the diagnostic ICD-9-CM codes, procedure codes, and other easily tabulated patient history (e.g., presence or absence of smoking, obesity). Although these characteristics could have an effect on patient outcome and costs, the large patient numbers, coupled with the fact that there is no reason to believe that the smoking and non-smoking patients were dissimilar enough to skew the results, lends confidence to the results. Obese patients were specifically excluded during the data acquisition so that the pure effects of smoking could be seen without the results being influenced by patient obesity, which is associated with increased cost, complications, and infections in spinal surgery patients (16, $17,19)$. The lower smoking rate observed in the patients in this study ( 10 vs. $30 \%$ of all surgical patients) may be explained by the exclusion of obese patients, as smokers have recently been shown to have higher rates of obesity and diabetes, especially in moderate and heavy smokers $(46,47)$. The low smoker rate in this study may represent another limitation with respect to the generalizability of these initial results.

\section{Conclusion}

Non-obese patients who smoke tobacco and were admitted to UHC hospitals from 2005 through 2011 with spinal dorsopathy, fracture, or congenital pathology had worse outcomes, more complications, and higher total direct costs than their non-smoking counterparts. The smokers in the curvature group also had higher 14- and 30-day readmission rates. This report also documents increased cost associated with smoking tobacco in spine patients; for smokers, the mean total cost for the four most common spine pathologies is $\$ 38,697$, whereas the same costs for a nonsmoker average $\$ 32,270(p<0.001)$. The Patient Protection and Affordable Care Act's emphasis on cost control and payment for performance, in addition to the universal goal of providing the best possible outcomes for patients, demands that surgeons advise their potential spine surgery patients to enroll in formal smoking cessation programs prior to consideration of surgery. Further studies are necessary to better define the association between smoking tobacco and worse outcomes in spine surgery patients.

\section{Acknowledgments}

We thank Kristin Kraus, M.Sc., for editorial assistance with the paper.

3. Martin A, Lassman D, Whittle L, Catlin A. Recession contributes to slowest annual rate of increase in health spending in five decades. Health Aff (Millwood) (2011) 30(1):11-22. doi:10.1377/hlthaff.2010.1032

4. Deyo RA, Gray DT, Kreuter W, Mirza S, Martin BI. United States trends in lumbar fusion surgery for degenerative conditions. Spine (Phila Pa 1976) (2005) 30(12):1441-5. doi:10.1097/01.brs.0000166503.37969.8a

5. U.S. Department of Health and Human Services. National Strategy for Quality Improvement in Health Care. Washington, DC: U.S. Department of Health and Human Services (2012). 
6. Delgado-Rodriguez M, Medina-Cuadros M, Martinez-Gallego G, GomezOrtega A, Mariscal-Ortiz M, Palma-Perez S, et al. A prospective study of tobacco smoking as a predictor of complications in general surgery. Infect Control Hosp Epidemiol (2003) 24(1):37-43. doi:10.1086/502113

7. Moores LK. Smoking and postoperative pulmonary complications: an evidencebased review of the recent literature. Clin Chest Med (2000) 21(1):139-46. doi:10.1016/S0272-5231(05)70013-7

8. Schwilk B, Bothner U, Schraag S, Georgieff M. Perioperative respiratory events in smokers and nonsmokers undergoing general anaesthesia. Acta Anaesthesiol Scand (1997) 41(3):348-55. doi:10.1111/j.1399-6576.1997.tb04697.x

9. Khullar D, Maa J. The impact of smoking on surgical outcomes. J Am Coll Surg (2012) 215(3):418-26. doi:10.1016/j.jamcollsurg.2012.05.023

10. Kamath AS, Vaughan Sarrazin M, Vander Weg MW, Cai X, Cullen J, Katz DA. Hospital costs associated with smoking in veterans undergoing general surgery. J Am Coll Surg (2012) 214(6):901.e-8.e. doi:10.1016/j.jamcollsurg.2012.01.056

11. Billeter AT, Polk HC Jr., Hohmann SF, Qadan M, Fry DE, Jorden JR, et al. Mortality after elective colon resection: the search for outcomes that define quality in surgical practice. J Am Coll Surg (2012) 214(4):436-43. doi:10.1016/ j.jamcollsurg.2011.12.018

12. Varela JE, Nguyen NT. Disparities in access to basic laparoscopic surgery at U.S. academic medical centers. Surg Endosc (2011) 25(4):1209-14. doi:10.1007/ s00464-010-1345-y

13. Dean PN, Hillman DG, McHugh KE, Gutgesell HP. Inpatient costs and charges for surgical treatment of hypoplastic left heart syndrome. Pediatrics (2011) 128(5):e1181-6. doi:10.1542/peds.2010-3742

14. Simorov A, Reynoso JF, Dolghi O, Thompson JS, Oleynikov D. Comparison of perioperative outcomes in patients undergoing laparoscopic versus open abdominoperineal resection. Am J Surg (2011) 202(6):666-70. doi:10.1016/j. amjsurg.2011.06.029

15. Simorov A, Shaligram A, Shostrom V, Boilesen E, Thompson J, Oleynikov D. Laparoscopic colon resection trends in utilization and rate of conversion to open procedure: a national database review of academic medical centers. Ann Surg (2012) 256(3):462-8. doi:10.1097/SLA.0b013e3182657ec5

16. Kalanithi PA, Arrigo R, Boakye M. Morbid obesity increases cost and complication rates in spinal arthrodesis. Spine (Phila Pa 1976) (2012) 37(11):982-8. doi:10.1097/BRS.0b013e31823bbeef

17. Pull ter Gunne AF, Hosman AJ, Cohen DB, Schuetz M, Habil D, van Laarhoven CJ, et al. A methodological systematic review on surgical site infections following spinal surgery: part 1: risk factors. Spine (Phila Pa 1976) (2012) 37(24):2017-33. doi:10.1097/BRS.0b013e31825bfca8

18. Veeravagu A, Patil CG, Lad SP, Boakye M. Risk factors for postoperative spinal wound infections after spinal decompression and fusion surgeries. Spine (Phila Pa 1976) (2009) 34(17):1869-72. doi:10.1097/BRS.0b013e3181adc989

19. Mehta AI, Babu R, Karikari IO, Grunch B, Agarwal VJ, Owens TR, et al. Young investigator award winner: the distribution of body mass as a significant risk factor for lumbar spinal fusion postoperative infections. Spine (Phila Pa 1976) (2012) 37(19):1652-6. doi:10.1097/BRS.0b013e318241b186

20. Hawn MT, Houston TK, Campagna EJ, Graham LA, Singh J, Bishop M, et al. The attributable risk of smoking on surgical complications. Ann Surg (2011) 254(6):914-20. doi:10.1097/SLA.0b013e31822d7f81

21. U.S. Surgeon General. Reports of the Surgeon General, U.S. Public Health Service. (2012). Available from: http://www.surgeongeneral.gov/library/reports/

22. Singh JA, Houston TK, Ponce BA, Maddox G, Bishop MJ, Richman J, et al. Smoking as a risk factor for short-term outcomes following primary total hip and total knee replacement in veterans. Arthritis Care Res (Hoboken) (2011) 63(10):1365-74. doi:10.1002/acr.20555

23. Neumayer L, Hosokawa P, Itani K, El-Tamer M, Henderson WG, Khuri SF. Multivariable predictors of postoperative surgical site infection after general and vascular surgery: results from the patient safety in surgery study. J Am Coll Surg (2007) 204(6):1178-87. doi:10.1016/j.jamcollsurg.2007.03.022

24. Gedaly R, McHugh PP, Johnston TD, Jeon H, Ranjan D, Davenport DL. Obesity, diabetes, and smoking are important determinants of resource utilization in liver resection: a multicenter analysis of 1029 patients. Ann Surg (2009) 249(3):414-9. doi:10.1097/SLA.0b013e31819a032d

25. Kelly KJ, Greenblatt DY, Wan Y, Rettammel RJ, Winslow E, Cho CS, et al. Risk stratification for distal pancreatectomy utilizing ACS-NSQIP: preoperative factors predict morbidity and mortality. J Gastrointest Surg (2011) 15(2):250-9. doi:10.1007/s11605-010-1390-9
26. Dimick JB, Chen SL, Taheri PA, Henderson WG, Khuri SF, Campbell DA Jr Hospital costs associated with surgical complications: a report from the privatesector National Surgical Quality Improvement Program. J Am Coll Surg (2004) 199(4):531-7. doi:10.1016/j.jamcollsurg.2004.05.276

27. Kalish RL, Daley J, Duncan CC, Davis RB, Coffman GA, Iezzoni LI. Costs of potential complications of care for major surgery patients. Am J Med Qual (1995) 10(1):48-54. doi:10.1177/0885713X9501000108

28. Vaughan-Sarrazin M, Bayman L, Rosenthal G, Henderson W, Hendricks A, Cullen JJ. The business case for the reduction of surgical complications in VA hospitals. Surgery (2011) 149(4):474-83. doi:10.1016/j.surg.2010.12.004

29. Brown CW, Orme TJ, Richardson HD. The rate of pseudarthrosis (surgical nonunion) in patients who are smokers and patients who are nonsmokers: a comparison study. Spine (Phila Pa 1976) (1986) 11(9):942-3. doi:10.1097/ 00007632-198611000-00015

30. Hadley MN, Reddy SV. Smoking and the human vertebral column: a review of the impact of cigarette use on vertebral bone metabolism and spinal fusion. Neurosurgery (1997) 41(1):116-24. doi:10.1097/00006123-199707000-00025

31. Mooney V, McDermott KL, Song J. Effects of smoking and maturation on long-term maintenance of lumbar spinal fusion success. J Spinal Disord (1999) 12(5):380-5. doi:10.1097/00002517-199910000-00005

32. Fehlings MG, Smith JS, Kopjar B, Arnold PM, Yoon ST, Vaccaro AR, et al. Perioperative and delayed complications associated with the surgical treatment of cervical spondylotic myelopathy based on 302 patients from the AOSpine North America Cervical Spondylotic Myelopathy Study. J Neurosurg Spine (2012) 16(5):425-32. doi:10.3171/2012.1.SPINE11467

33. Schwab FJ, Hawkinson N, Lafage V, Smith JS, Hart R, Mundis G, et al. Risk factors for major peri-operative complications in adult spinal deformity surgery: a multi-center review of 953 consecutive patients. Eur Spine J (2012) 21(12):2603-10. doi:10.1007/s00586-012-2370-4

34. Keorochana G, Laohacharoensombat W, Wajanavisit W, Chanplakorn P, Woratanarat P, Chatchaipun P. Functional outcome after decompression and instrumented arthrodesis in degenerative lumbar spinal stenosis: factors influencing unsuccessful outcome change. J Med Assoc Thai (2011) 94(12): 1487-94.

35. Nassr A, Eck JC, Ponnappan RK, Zanoun RR, Donaldson WF III, Kang JD. The incidence of $\mathrm{C} 5$ palsy after multilevel cervical decompression procedures: a review of 750 consecutive cases. Spine (Phila Pa 1976) (2012) 37(3):174-8. doi:10.1097/BRS.0b013e318219cfe9

36. Kalb S, Reis MT, Cowperthwaite MC, Fox DJ, Lefevre R, Theodore N, et al. Dysphagia after anterior cervical spine surgery: incidence and risk factors. World Neurosurg (2012) 77(1):183-7. doi:10.1016/j.wneu.2011.07.004

37. Pearson A, Lurie J, Tosteson T, Zhao W, Abdu W, Weinstein J. Who should have surgery for spinal stenosis? Spine (Phila Pa 1976) (2012) 37(21):1791-1802. doi:10.1097/BRS.0b013e3182634b04

38. Sanden B, Forsth P, Michaelsson K. Smokers show less improvement than nonsmokers two years after surgery for lumbar spinal stenosis: a study of 4555 patients from the Swedish spine register. Spine (Phila Pa 1976) (2011) 36(13):1059-64. doi:10.1097/BRS.0b013e3181e92b36

39. Cobo Soriano J, Sendino Revuelta M, Fabregate Fuente M, Cimarra Diaz I, Martinez Urena P, Deglane Meneses R. Predictors of outcome after decompressive lumbar surgery and instrumented posterolateral fusion. Eur Spine J (2010) 19(11):1841-8. doi:10.1007/s00586-010-1284-2

40. Peolsson A, Vavruch L, Oberg B. Predictive factors for arm pain, neck pain, neck specific disability and health after anterior cervical decompression and fusion. Acta Neurochir(Wien) (2006) 148(2):167-73. doi:10.1007/s00701-005-0660-x

41. Lindstrom D, Sadr Azodi O, Wladis A, Tonnesen H, Linder S, Nasell H, et al. Effects of a perioperative smoking cessation intervention on postoperative complications: a randomized trial. Ann Surg (2008) 248(5):739-45. doi:10. 1097/SLA.0b013e3181889d0d

42. Davis FM, Laurenson VG, Gillespie WJ, Wells JE, Foate J, Newman E. Deep vein thrombosis after total hip replacement. A comparison between spinal and general anaesthesia. J Bone Joint Surg Br (1989) 71(2):181-5.

43. Moller AM, Villebro N, Pedersen T, Tonnesen H. Effect of preoperative smoking intervention on postoperative complications: a randomised clinical trial. Lancet (2002) 359(9301):114-7. doi:10.1016/S0140-6736(02)07369-5

44. Thomsen T, Tonnesen H, Moller AM. Effect of preoperative smoking cessation interventions on postoperative complications and smoking cessation. Br J Surg (2009) 96(5):451-61. doi:10.1002/bjs.6591 
45. Thomsen T, Villebro N, Moller AM. Interventions for preoperative smoking cessation. Cochrane Database Syst Rev (2010) (7):CD002294. doi:10.1002/ 14651858.CD002294.pub3

46. Chiolero A, Jacot-Sadowski I, Faeh D, Paccaud F, Cornuz J. Association of cigarettes smoked daily with obesity in a general adult population. Obesity (Silver Spring) (2007) 15(5):1311-8. doi:10.1038/oby.2007.153

47. Clair C, Chiolero A, Faeh D, Cornuz J, Marques-Vidal P, Paccaud F, et al. Dosedependent positive association between cigarette smoking, abdominal obesity and body fat: cross-sectional data from a population-based survey. BMC Public Health (2011) 11:23. doi:10.1186/1471-2458-11-23

\section{Appendix}

TABLE A1 | Complications per 1,000 patient encounters for spinal disease 2005-2011.

Complication description

Rate

per 1,000

Postoperative pulmonary compromise

38.97

Mechanical complications due to device or implant

27.62

Other complications of procedures

Aspiration pneumonia

Venous thrombosis/pulmonary embolism

Nosocomial pneumonia

Miscellaneous complications

Sepsis

Wound infection

Post-procedure hemorrhage or hematoma

$\begin{array}{ll}\text { Acute myocardial infarction occurring during hospital stay } & 9.07\end{array}$

$\begin{array}{ll}\text { Procedure-related perforations or lacerations } & 6.38\end{array}$

$\begin{array}{ll}\text { Cellulitis or decubitus ulcer } & 5.18\end{array}$

$\begin{array}{ll}\text { Reopening of surgical site } & 4.47\end{array}$

$\begin{array}{ll}\text { Postoperative stroke } & 4.13\end{array}$

$\begin{array}{ll}\text { Gastrointestinal hemorrhage } & 4.04\end{array}$

$\begin{array}{ll}\text { Central or peripheral nervous system } & 3.85\end{array}$

$\begin{array}{ll}\text { Postoperative infections not pneumonia/wound } & 3.28\end{array}$

$\begin{array}{ll}\text { Catheter-associated urinary tract infection } & 1.49\end{array}$

$\begin{array}{ll}\text { Postoperative urinary tract complication } & 1.17\end{array}$

$\begin{array}{ll}\text { Postoperative cardiac abnormality except acute myocardial infarction } \quad 0.82 & 0.69\end{array}$

$\begin{array}{ll}\text { Hospital-acquired C. diff enteritis } & 0.69\end{array}$

$\begin{array}{ll}\text { Postoperative coma or stupor } & 0.58\end{array}$

$\begin{array}{ll}\text { Adverse events due to anesthesia } & 0.36\end{array}$

$\begin{array}{ll}\text { Postoperative physical and metabolic derangements } & 0.23\end{array}$

$\begin{array}{ll}\text { Readmission for infection due to previous care } & 0.22\end{array}$

Infection/inflammation due to internal device, implant, graft $\quad 0.14$

$\begin{array}{ll}\text { Readmission for other complications of internal device, implant, graft } \quad 0.07 & 0.03\end{array}$

$\begin{array}{ll}\text { Shock or cardiorespiratory arrest } & 0.03\end{array}$

$\begin{array}{ll}\text { Post- or intraoperative shock due to anesthesia } & 0.01\end{array}$

Rates for complications with rates $>1$ per 100,000.
Conflict of Interest Statement: The authors declare that the research was conducted in the absence of any commercial or financial relationships that could be construed as a potential conflict of interest.

Copyright (c) 2015 Bisson, Bowers, Hohmann and Schmidt. This is an open-access article distributed under the terms of the Creative Commons Attribution License (CC $B Y)$. The use, distribution or reproduction in other forums is permitted, provided the original author(s) or licensor are credited and that the original publication in this journal is cited, in accordance with accepted academic practice. No use, distribution or reproduction is permitted which does not comply with these terms. 